\title{
Clínica da identidade: da cosmovisão pataxó à luta por emancipação
}

\author{
Simone Jörg* (1) \\ Universidade de São Paulo, Departamento de Psicologia Social e do Trabalho, São Paulo, SP, Brasil
}

\begin{abstract}
Resumo: Constitui-se o foco deste artigo apresentar o processo de construção identitária com sentido emancipatório a partir da cosmovisão e luta por território do povo indígena Pataxó, única etnia que conseguiu resistir no extremo-sul da Bahia. A pesquisa demonstrou que a luta por reconhecimento, tanto no plano jurídicomoral quanto no da estima-social, constitui os processos emancipatórios que caracterizam as identidades políticas da etnia indígena Pataxó.
\end{abstract}

Palavras-chave: clínica, identidade, cosmovisão, território, reconhecimento.

\section{A proposta de uma "Clínica da Identidade" a partir de uma psicologia descolonizadora}

Historicamente, a Psicologia parte de um modelo de homem hegemônico, produto de um momento específico da cultura ocidental. Isto posto, é urgente considerar as questões indígenas com enfoque na diversidade que ela requer, a partir de novos olhares criando, assim, referenciais adequados para atuação profissional do psicólogo junto a essas comunidades (Conselho Regional de Psicologia da 6 Região, 2010).

A subjetividade hegemônica na nossa sociedade é uma subjetividade urbanizada, globalizada, marcada pela influência onipresente das multinacionais, numa dinâmica em que nós somos estimulados a consumir incessantemente, assim como consumidos pelos objetos que compramos.

Há uma subjetividade colonial presente nas próprias pessoas, em nós mesmos, numa repetição que é fruto de mais de 500 anos dessa visão de mundo que ainda adotamos, que é predatória com relação aos demais seres humanos e à natureza (Maldos, 2010).

Moreira, Romagnoli e Neves (2007), em "O surgimento da clínica psicológica: da prática curativa aos dispositivos de promoção da saúde", delineiam o panorama histórico das mudanças da prática clínica do psicólogo como prática clínica individual de consultório, em contraposição a um modelo de clínica chamada social, que sustenta novas atuações no campo da Psicologia no Brasil. Para além de uma cisão entre clínica e política, presente no modelo tradicional - embora no espaço clínico se entre em contato com modos de subjetivação que buscam, de alguma maneira, criar alternativas de retificação, o que significa que o fazer clínico é, também, um fazer político, uma vez que ele é transformador-, ainda perpetua-se a cisão entre

\footnotetext{
* Endereço para correspondência: simonejorg@gmail.com
}

clínica e política e, nesse sentido, as autoras defendem uma definição de clínica social com prática ética e política das intervenções, comprometida com a promoção da saúde e engajada na realidade social brasileira.

Estamos chamando de "clínica" uma abordagem que extrapola o "campo" específico da prática clínica em psicologia, em concordância com Figueiredo (1996), ao afirmar que a clínica psicológica se caracteriza não pelo local em que se realiza - o consultório -, mas pela qualidade da escuta e da acolhida que se oferece ao sujeito: a escuta e a acolhida do excluído do discurso; o que, no nosso entender, demanda uma postura diante do outro, um "olhar".

Para isso, é necessário, segundo Moreira etal.(2007), tomar a clínica como plano de produção do coletivo, melhor dizendo, uma forma de resistência, como sustentação da alteridade: a clínica social.

O desafio e proposta deste trabalho repõem o desejo de Jörg $(2011,2017)$ de construção de um olhar sensível e crítico capaz de contribuir com elementos para pensar a configuração de uma psicologia social clínica ao pesquisar a "clínica da identidade".

Qual o sentido da luta por território para o povo Pataxó e no que esta luta implica em termos da sua identidade indígena e no que diz respeito à sua emancipação é uma questão crucial para se compreender a produção de sentidos subjetivos.

Da perspectiva dialética, a subjetividade não pode ser coisificada em termos de subjetividade em uma instância, entidade ou tipo de processo concreto; não se substancializa em atributos universais. Ela representa uma produção de sentidos inseparável do contexto e das formas complexas de organização social que estão por trás dos vários espaços de ação social que se integram em todas as dimensões do sujeito, incluindo corporal, segundo González Rey (2009). 
Para a construção desse "outro" olhar, é necessário compreender a cosmovisão pataxó, intrínseca à luta pelo território, na direção de uma psicologia descolonizadora com pretensões reflexivas de base crítica-analítica do contexto cultural, político e econômico que influenciam e são influenciados pela cultura pataxó.

A cultura como resposta e resistência à opressão é uma dimensão fundamental para a construção da identidade, pois, segundo Ciampa (1986/2009), trata-se de um processo relacional e histórico, um contínuo dar-se num processo de interação humana, em constante transformação, de acordo com as experiências, situações, relações com grupos e pessoas e com o significado atribuído aos papéis desempenhados e o reconhecimento social destes.

Para Dussel (1997), a civilização pode se universalizar, ao passo que a cultura pode ser "compreendida" quando nos "incorporamos" à comunidade que a vive. Nesse sentido, a cultura é intransmissível a outros. O que ocorre é um viver a partir de dentro, que é aprendido por tradição e, acrescentaríamos, na luta. De modo que, se houver uma acumulação, ela se realiza na tradição vivida, que é vivida pela incorporação e comunicada na intersubjetividade.

Lima (2009) menciona que, quando as políticas de identidade são utilizadas como instrumento de regulação, "estamos nos referindo às situações onde essas políticas são utilizadas de forma ideológica para a manutenção de uma determinada realidade instituída, não possibilitando a expressão da subjetividade individual" (p. 150) e, no caso dos Pataxó, poderíamos acrescentar que impossibilita a expressão da subjetividade coletiva, da própria etnia. $\mathrm{O}$ autor ainda salienta que "as identidades pressupostas oferecidas por determinadas políticas de identidade podem se tornar um impulso para a superação de outra personagem posta (segregadora) de forma negativa e limitadora" (Lima, 2009, p. 154).

\section{Metodologia}

Na concepção de Carlos Brandão (1984), espera-se que o pesquisador busque "conviver" com o outro em seu mundo, sentindo e pensando com ele, e que participe com seu trabalho para "empreender para servir", e, quando a lógica da cultura investigada passa a ser mais importante que a do próprio pesquisador, diz-se tratar-se de observaçãoparticipante, amplamente utilizada nesta pesquisa.

Nesse contexto metodológico de pesquisa, a palavra "participação" significa que há possibilidade do envolvimento direto do trabalho das pessoas da comunidade na produção do conhecimento social sobre sua realidade.

Quanto à postura de "observadora participante" (Malinowski, 1978), esta permite construir uma rede de informações dotadas de sentidos próprios do contexto do objeto da pesquisa, capaz de fornecer elementos prévios para poder interagir com maior consentimento dos entrevistados, que também pesquisam, na pesquisadora, seu interesse e conhecimento da realidade local.
Angrosino (2009) considera a naturalidade da observação participante um elemento que ameniza a intervenção subjetiva do observador, pois não costuma solicitar que as pessoas façam nada fora do comum. Com isso, espera-se que, com o tempo, a presença dele ou dela deixe até de ser um fato notável e que as pessoas simplesmente sigam normalmente com suas vidas. $\mathrm{O}$ autor sublinha que a observação participante se configura no ato de perceber as atividades e os inter-relacionamentos das pessoas no cenário de campo por meio dos cinco sentidos do pesquisador.

Na qualidade de observadora-participante, disponho-me a realizar as mais diversas tarefas, como ajudar a varrer alguns locais da Reserva e a carregar o lixo, ao som de comentários de alguns indígenas elogiando minha força de vontade e disposição em ajudar; na pintura de um totem de um pajé que fica no interior do kijeme (construção indígena pataxó utilizada para moradia ou eventos como palestra, ou rituais espirituais), onde se dança o awê (ritual espiritual pataxó); a carregar folhas de coqueiro para enfeitar o caminho de entrada da Reserva; a retirar o tawá, um barro amarelo das falésias do local, para o ritual do batismo realizado na festa do Araguaks $\tilde{a}$ (festa em que se comemora a retomada da terra indígena da Reserva da Jaqueira); a visitar outras aldeias pataxó quando convidada; a participar dos rituais sagrados e a permanecer na convivência dos Pataxó quando estão fazendo seu artesanato, alimentando-se ou conversando. A conversa sempre era muito descontraída, repleta de risadas e, em alguns momentos, muitas frases em patxôhã (língua pataxó que, segundo os Pataxó, estava "adormecida") eram incompreensíveis para mim. Certa vez, pude ouvir uma conversa que me soou muito engraçada, quando um dos jovens Pataxó comentava que o não indígena ainda tem em seu imaginário a expectativa de encontrar o "índio nu", e ele, então, em tom de brincadeira, mencionou que seria engraçado se todos eles começassem a andar nus numa região turística como a de Porto Seguro, na Bahia. Naquele momento, todos riram muito; e eu reflito sobre o raciocínio crítico que aquele indígena estava elaborando, de forma irônica, sobre uma expectativa presa a um imaginário colonizador que ainda expressa o desejo por alguns em ver os índios da pré-colonização na contemporaneidade.

No processo indissociável entre indivíduo e sociedade na formação da identidade, em que ambas se constituem, utilizei como método a "História de Vida" (Becker, 1997) (Ciampa, 2009) que melhor confere essa noção de processo e contínua transformação. Ciampa (2009) considera que, na narrativa de história de vida, método por ele adotado nas pesquisas de identidade, "o singular materializa o universal na unidade do particular" (p. 217).

A entrevista com base na narrativa de história de vida, em vez de tentar uma reconstrução combinada de um evento específico como na história oral, procura ver o passado através do específico microcosmo da vida de um indivíduo, e este pode ser um membro "típico" ou "representativo" 
de sua comunidade - de forma que sua história de vida simbolize a de todos cujas histórias não tenham sido registradas - ou uma pessoa "extraordinária" (que representa os valores e aspirações do grupo (Ciampa, 1986/2009).

Foi utilizado na pesquisa o critério central para decidir quantos sujeitos para as entrevistas seriam necessárias, o que Gaskell (2008, p. 71) chamou de "ponto de saturação do sentido", ou seja, começo as entrevistas sem um número predefinido de participantes e, quando não obtenho mais novos dados ou percebo homogeneidade nas narrativas, encerro as entrevistas.

Seguindo o que é sugerido para pesquisas dessa natureza (Jovchelovitch \& Bauer, 2008), as entrevistas foram registradas com auxílio do gravador e transcritas literalmente.

Os indígenas que participaram das entrevistas assumiam cargos de superintendência de secretarias de assuntos indígenas, de saúde, direção de escola indígena, professores indígenas de patxohã, agentes de saúde indígena, caciques, lideranças e indígenas com conhecimento de ervas medicinais.

A "amostra" de sujeitos foi composta por 22 entrevistados, entre jovens e adultos, do sexo masculino e feminino, de faixas etárias que variaram entre 18 e 60 anos; de ensino fundamental a ensino superior; somente dois sujeitos não eram alfabetizados.

Com exceção de um único entrevistado que solicitou sigilo, pois era ameaçado de morte, todos os demais expressaram sua condição por participar da pesquisa na qual sua identidade fosse revelada.

\section{Análise de sentidos}

Realizada segundo a abordagem da psicologia sócio-histórica na análise do material qualitativo, visando a apreender os sentidos que constituem o conteúdo do discurso dos sujeitos informantes por meio do que chamamos de núcleos de significação. Os significados referem-se aos conteúdos instituídos, mais fixos, compartilhados, que são apropriados pelos sujeitos, configurados a partir de suas próprias subjetividades (Aguiar \& Ozella, 2006).

A discussão de significado e sentido requer a compreensão de sua constituição por uma unidade contraditória do simbólico e do emocional. Portanto, na perspectiva de melhor compreender o sujeito, os significados constituem o ponto de partida, mas contêm mais do que aparentam, e somente por meio de um trabalho de análise e interpretação é possível caminhar para as zonas mais instáveis, fluidas e profundas, ou seja, para as zonas de sentido. E, como menciona Gonzalez Rey (2003), o sentido subverte o significado, pois ele não se submete a uma lógica racional externa. O sentido diz respeito a necessidades que, muitas vezes, ainda não se realizaram, mas que mobilizam o sujeito, constituem seu ser, geram formas de colocá-lo na atividade. O sentido deve ser entendido como um ato do homem mediado socialmente.
A categoria sentido destaca a singularidade historicamente construída (Aguiar \& Ozella, 2006).

\section{Terra indígena, território, territorialidade e desterritorialização}

Território não é apenas anterior a terra, e terra não é tão somente parte de um território; são duas noções absolutamente distintas. Santilli (2005) nos ensina que a ocupação da terra por parte das comunidades indígenas se baseia em padrões de propriedade e de uso diferentes dos nossos. A terra não consiste apenas em um meio de produção. Ela é o espaço em que se conformam modos de vida que não são baseados na ocupação intensiva e não é algo do qual se possa desfazer em função da recorrência a outras alternativas.

Quando temos em mente a ocupação tradicional que os povos indígenas exercem sobre determinado território, a categoria mais apropriada para pensarmos essa relação é “territorialidade", definida por Little (2002) como "o esforço coletivo de um grupo social para ocupar, usar, controlar e se identificar com uma parcela específica de seu ambiente biofísico, convertendo-se assim em seu "território" (p. 3).

Segundo Carlos Frederico Marés de Souza Filho, "terra" se refere a "propriedade" individual, portanto é um conceito eminentemente civilista, privado; enquanto "território" faz menção à jurisdição de um espaço geográfico, evidenciando seu caráter coletivo, público. Sobre o conceito jurídico de território, enfatiza-se a clássica postura que o situa como um dos elementos que formam o Estado, junto com o povo e o governo. Dessa forma, o território define os limites físicos para o poder do estado, o que quer dizer jurisdição e soberania. A terra é, para os povos indígenas, um "espaço de vida e liberdade". O espaço entendido como lugar de realização da cultura. As sociedades humanas e, neste caso, as sociedades indígenas, constroem seus conhecimentos a partir de cosmologias próprias, elaboradas coletivamente com as experiências sociais, o que demonstra visões de mundo não compatíveis com o modelo individualista ocidental (Dantas \& Morais, 2008). Assim, "a concepção da territorialidade indígena e dos povos tradicionais se pauta por princípios diferentes daqueles que regem o direito da propriedade privada" (Little, 2002, p. 11).

Sobre o direito a terra, a Constituição resgatou uma interpretação que já existia desde 1680, que trata do direito originário. Isso quer dizer que o direito dos povos indígenas sobre a terra já existe, ele vem em primeiro lugar. O território constitui a identidade étnica do povo Pataxó num nível transcendental, ou seja, os Pataxó pertencem ao território por um princípio espiritual, pela ligação com os antepassados que também marcam sua ligação com o território pataxó.

O processo de "desterritorialização" enquanto fenômeno vinculado à globalização comporta diferentes interpretações, por diferentes autores 
dentro e fora da geografia, as quais envolvem entendimentos que se dão na contraposição entre a fixidez e a fluidez, ou entre território e rede. Ao tratarmos da desterritorialização como domínio das redes, dos fluxos, da mobilidade em contraposição ao locus da estabilidade e do enraizamento, ignoramos que as redes e a mobilidade que elas proporcionam são componentes indissociáveis do território.

Quando a desterritorialização é percebida como perda de referenciais espaciais, concretos, sob o domínio das relações imateriais, o território é tido como fundamento material/espacial da sociedade, confundido assim com a ideia de espaço geográfico (Haesbaert, 1999).

Trazendo a desterritorialização para os grupos subalternos ou excluídos, podemos pensar o movimento indígena pela delimitação e controle de suas reservas e, mesmo tendo o domínio sobre determinado espaço, podem faltar ao grupo indígena as referências territoriais de sua cultura, o caráter simbólico-cultural vinculado ao território, que traz no "imaginário coletivo" as lembranças condensadas em parcelas do espaço (um rio, o cantar de um pássaro, um trecho de floresta - espaços de espíritos de seus ancestrais).

Haesbaerth (1999) assevera que a perda dos territórios implica, na maioria dos casos, na fragmentação dos indivíduos que compõem as comunidades. Ao serem desconectados em relação ao espaço e aos seus recursos naturais, estes perdem muitos de seus referenciais culturais de identidade. Nessas situações, as dimensões econômicas, política e cultural da vida social podem se desarticular, enfraquecendo a unidade política dos grupos e tornando bem mais ambíguas as relações que as coletividades estabelecem com seus territórios.

\section{O Monte Pascoal e a presença dos Pataxó no extremo sul da Bahia}

Os registros de cartas e relatos do período colonial já reconheciam o Monte Pascoal como área habitada pelos Pataxó, servindo-lhes, inclusive, de ponto de referência e guia, uma vez que servia de orientação pela indicação do vento para nortear viajantes e pescadores (Carvalho, 1977).

Para Sampaio (2010), mesmo com a convivência da diversidade étnica, para esta comunidade indígena prevaleceu o etnômio Pataxó, por apresentar maior contingente de representantes dessa etnia e por sua aldeia estar situada em território tradicionalmente conhecido como do povo Pataxó. De modo geral, esses indígenas foram marcados por uma traumática e difícil conquista pelos colonizadores, analisa Carvalho (1977), considerados extintos segundo relatos de antropólogos no início do século XX. Isso se deu em decorrência de genocídios bacteriológicos praticados por plantadores de cacau, ao espalharem roupas infectadas por hanseníase e varíola entre as matas do rio de Contas e o Pardo, no desejo de darem cabo aos últimos bandos que viviam isolados de forma autônoma, conforme Ribeiro (1970).

\section{O Fogo de 51: o massacre}

A conquista desses povos indígenas do sul da Bahia é uma longa história de mais de cem anos; no que diz respeito ao extremo sul, porém, tudo indica que, já em meados do século XIX, a maioria da população indígena sobrevivente vivia junto às vilas coloniais costeiras - de Santa Cruz Cabrália a Porto Alegre, atual Mucuri -, para onde fora trazida na tentativa de ser submetida ao trabalho a serviço dos regionais. Em 1861, contudo, preocupado com os constantes conflitos entre estes e os indígenas, e, provavelmente, também com a possibilidade legal de os últimos reivindicarem as terras que ocupavam, o presidente da Província da Bahia determinou a concentração compulsória de toda a população indígena da região numa única aldeia, a ser estabelecida no ponto médio daquela costa, junto à embocadura do rio Corumbau. Esta é, seguramente, a origem da atual aldeia de Barra Velha (Carvalho,1977).

Os Pataxó de Barra Velha romperam o século XX, muito certamente, como a única comunidade indígena na região, e aí viveram isolados de qualquer contato mais regular com a população envolvente, além da dos diminutos povoados vizinhos. Com efeito, entre $1861 \mathrm{e}$ 1951, são escassíssimas as referências existentes sobre essa aldeia perdida numa das regiões então mais isoladas do estado (Carvalho, 1977). O isolamento dos Pataxó seria dramaticamente rompido em 1951 com o massacre na "aldeia mãe de Barra Velha" totalmente incendiada, em um episódio fartamente noticiado pela imprensa de Salvador à época.

\section{Territorialização pataxó: da dispersão à aldeia de Coroa Vermelha}

Nitynawã Pataxó (2011), liderança da "Reserva Pataxó da Jaqueira" (em Porto Seguro - BA), em seu livro As guerreiras na história pataxó, relata que, após o massacre de 1951, muitos índios se refugiaram em outros locais, assim formando novas aldeias, como a de Coroa Vermelha. Com a consciência de que a terra sempre fora dos indígenas, a autora Nitynawa Pataxó (2011) relata a luta pela demarcação da Terra Indígena Pataxó de Coroa Vermelha durou por 24 anos até que, em 1997, foi homologada. Durante esse período, o povo Pataxó passou por várias mudanças de costumes, moradia, língua, e integração à sociedade.

Pacheco de Oliveira (1999) sustenta que as fronteiras territoriais dos povos indígenas são razoavelmente flexíveis. Oscilam constantemente em razão de mudanças demográficas, expedições guerreiras ou movimentos migratórios de natureza variada. A demanda dos grupos indígenas sobre a terra pode sofrer alterações significativas em função da convergência circunstancial de interesses e da capacidade de resistência diante da pressão de outras sociedades vizinhas, portadoras de características semelhantes. As terras indígenas estão permanentemente sendo revistas, sofrendo acréscimos, diminuições, junções e 
desacertos do Estado ou de iniciativas espúrias de interesses contrariados, porém essas ocorrências fazem parte do próprio caráter do processo de territorialização de uma comunidade indígena no interior do marco institucional estabelecido pelo Estado.

Em 1997, a Terra Indígena Pataxó de Coroa Vermelha, que estava em processo de demarcação, incluía a área hoje denominada Reserva Pataxó da Jaqueira, uma área de mata atlântica de 827 hectares. A retomada da Jaqueira contribuiu para apressar a homologação da Terra Indígena Coroa Vermelha.

\section{Reserva Pataxó da Jaqueira: o coração do povo Pataxó}

O processo de retomada ocorreu porque, na época, aquele que se dizia dono da terra (a empresa Góes Cohabita) começou a degradar a área que já estava em processo de demarcação para área indígena. Como sua intenção era realizar loteamentos, começou um intenso processo de desmatamento. Em 11 de outubro de 1997, os indígenas se reuniram e ocuparam a área com a ajuda das aldeias Caramuru, Paraguaçu, Boca da Mata, Barra Velha, Mata Medonha e a sede Coroa Vermelha. Inspiradas pela ideia de criar um trabalho de conscientização e valorização da cultura indígena pataxó, as irmãs Nitynawã, Nayara e Jandaya saíram à procura de pessoas que as ajudassem.

Abrir para a visitação de turistas foi a forma encontrada para manter a preservação do local. Para tanto, são realizadas palestras de educação ambiental e cultural, trabalho conhecido como etnoturismo, já que é realizado em uma área indígena. Assim, a visita não se restringe a passeio na mata, mas também se volta ao conhecimento da cultura pataxó, pois “o nosso principal objetivo é o fortalecimento da cultura e a preservação da mata e o etnoturismo é um complemento que nos ajuda a manter a Reserva", segundo Nitynawã Pataxó (2011, p. 44).

Como o processo histórico foi determinante nas perdas da cultura pataxó, o despertar para a afirmação de uma identidade pataxó faz surgir o desejo de revitalizar as tradições adormecidas (dentre elas a própria língua, o patxohã, adormecida desde o "massacre de 51 " e despertada com a ajuda dos anciãos aos mais jovens), restando-lhes a utilização da memória coletiva para seu processo inventivo. Mesmo porque "essas práticas são reguladas por regras tácitas ou abertamente aceitas, de natureza ritual ou simbólica que visam inculcar certos valores e normas de comportamento por meio da repetição, o que implica, automaticamente, uma continuidade em relação ao passado" (Hobsbawn \& Ranger, 1984, p. 10).

\section{Construção e fortalecimento da identidade étnica dos Pataxó e as personagens indígenas da Reserva Pataxó da Jaqueira}

Fredrik Barth, na década de 1960, substituiu uma concepção estática da identidade étnica por uma concepção dinâmica. Em seu ponto de vista, essa identidade, como qualquer outra identidade coletiva (bem como a identidade pessoal individual), é construída e transformada na interação de grupos sociais por meio de processos de exclusão e inclusão que estabelecem limites entre tais grupos, definindo os que os integram ou não. Logo, importa considerar os processos de organização social pelos quais se mantêm de forma duradoura as distinções entre "nós" e "os outros", mesmo quando mudam as diferenças que, para "nós", assim como para "os outros", justificam e legitimam tais distinções. Para Barth (1969), os processos que carregam "traços que levamos em conta não são a soma das diferenças 'objetivas' mas tão somente aqueles que os próprios atores consideram como significativos" (p. 11). Desse modo, as mesmas características diferenciadas podem mudar de significação ou perder a significação no decorrer da história do grupo; e diversas características podem se suceder adquirindo a mesma significação (Poutignat \& Streiff-Fenart, 1998).

Barth faz da etnicidade um processo organizacional ao tomar o grupo étnico do ponto de vista da atribuição de categorias de "Nós" e de "Eles", assim, de um ponto de vista analítico, torna-se impossível distingui-lo a priori e por definição de outras formas de identidades coletivas. O foco depositado nas fronteiras reserva para a noção de etnicidade sua ancoragem na noção de grupo, mas salienta a dimensão processual. A especificidade da organização social étnica decorre do papel que nela desempenham os contrastes culturais, indissociável do processo de manifestação de identidades. Vale destacar que tais processos são organizacionais precisamente na medida em que não derivam da psicologia dos indivíduos, mas da constituição de espaços cênicos e das operações externas que os atores aí realizam uns com os outros. Porque é nesses espaços que os atributos culturais adquirem valor expressivo (e podem então ser altamente seletivos), não como reveladores de uma realidade subjetiva, até mesmo inefável, mas como reivindicação a ser julgada como "certo tipo de pessoa", reivindicação que necessita ser publicamente validada e ratificada e que supõe um idioma convencional comum, um partilhar comum de sentidos capaz de ensejar um discurso coletivo de validação do "tipo de pessoa". Em associação à teoria de identidade de Ciampa, poderíamos falar em certo "tipo de personagem" que é construída nas condições concretas da existência social, econômica, política e cultural. E, por serem tais condições sempre mutáveis, as personagens são construídas, descontruídas e reconstruídas conforme o "sentido" que encontra para sua constituição no espaço cênico ou interacionista capaz de possibilitar ou impedir o processo de metamorfose das personagens que, numa relação dialética, caminharão conforme nos ensinou Ciampa (1986/2009), para a morte física ou simbólica ou para a alterização identitária.

É possível perceber a construção e o fortalecimento da identidade étnica dos Pataxó da 
Reserva Pataxó da Jaqueira, na medida em que, por meio da atuação de suas personagens, reconquistam seu território (com a ajuda de comunidades pataxó de outras aldeias), que é a base para a organização em torno de um "projeto comum à aldeia", fundamentado em valores comuns guiados pelo sentimento de pertença a uma mesma origem; de um povo que conhece sua história e sabe se dizer; personagens que retomam os costumes respaldados pela memória coletiva dos costumes e da convivência; e identificam um projeto sustentável por meio do etnoturismo, capaz de garantir os recursos necessários para manter a sobrevivência do grupo - portanto a perpetuação biológica e de suas tradições, fundamentais para a permanência de um sentimento de "nós", constitutivo de uma identidade étnica. Para além do resgate cultural, a identidade étnica dos Pataxó da Reserva Pataxó da Jaqueira se reinventa num movimento contínuo de "estar-sendo" no devir identitário, segundo Ciampa (1986/2009), e que articula estratégias e rede de negociações para se manter, primeiramente pela reconquista de seu território e de seus costumes e, posteriormente, por meio de projetos de sustentabilidade via órgãos públicos e empresas privadas, além de normatizações que sustentam a novas personagens.

Logo falar de uma identidade étnica, estabelecendo um paralelo com a teoria de identidade de Ciampa e a teoria da etnicidade como forma de interação social de Barth, é falarmos de uma identidade concreta, atravessada por múltiplas determinações, espaciais e temporais, é um ser-no-mundo e um ser temporal que se constitui nas interações que se dão nas fronteiras entre o "eu" e o "outro", e que, para cada um dos Pataxó, sintetiza em si a historicidade de um contexto social, político, econômico e cultural em contínuo movimento. Conforme Ciampa (2009), "Mesmo um fato ocorrido, que é definitivamente irrecorrível, tem desdobramentos e significados imprevisíveis, bem como transformações infindáveis. De um lado o homem é ser-posto" (p. 207), por sua origem, experiências e sentimentos comuns compartilhados na coletividade, "de outro é vir-a-ser, é concreto" (p. 207), em constante transformação e construção na luta pela garantia de condições concretas para a permanência/reivenção de sua identidade étnica conforme os sentidos e valores do grupo.

\section{Fetichismo da personagem indígena pataxó tradicional?}

A Reserva Pataxó da Jaqueira tem, para os Pataxó entrevistados, o sentido de preservação de sua história, costumes, tradição, cultura e valores. Contudo há a preocupação com uma suposta percepção distorcida que se constrói do indígena, de que este tem uma "imagem exótica", propagada pelos indígenas da reserva, na medida que, no seu cotidiano, os indígenas não usam os trajes tradicionais. Ainda assim, tem valor como narrativa histórica de suas origens, que é a essência da Reserva da Jaqueira, "manter viva a história do povo Pataxó". Nesse sentido, é "uma referência às outras aldeias pataxó e povos indígenas", no que diz respeito à afirmação cultural (pintura, trajes indígenas, dança do awê) e preservação ambiental, tendo reconhecimento nacional e internacional.

As personagens necessitam de normatização, segundo Ciampa (1986/2009), para conservar as identidades produzidas, fenômeno este que ele identificou como "re-posição", que pode ter valor positivo, quando favorece um sentido de direção aos indivíduos, ou sentido negativo, quando reduz estes a uma única personagem, eliminando assim o jogo que articula igualdade e diferença, e que dificulta ou impede o processo de emancipação em que um indivíduo atinge a condição de ser-para-si (tornar-se sujeito) capaz de sua própria autodeterminação. Isso gera o que o autor irá designar de identidade-mito ou fetichismo da personagem, que corresponde ao mundo da mesmice (da não-mesmidade), movimento de re-posição identitária que pode se dar como consciente forma de estabilidade ou insconsciente compulsão à repetição, e da má infinidade (a não superação das contradições), em que a própria atividade exercida pela personagem deixa de ser desempenhada.

A questão teórica da re-posição identitária que está a serviço da manutenção da estrutura social se apresenta diante da "nova realidade" dos indígenas que, no cotidiano, não usam o traje tradicional ou não estão pintados, conservando personagens-heterônomas, numa relação de submissão ao imaginário colonialista (dominação europeia) e que mantém, no imaginário social coletivo, uma personagem estatizada, fetichizada de um "indígena de 1500" na contemporaneidade.

As considerações sobre a re-posição nos fornece a dimensão da representação do estar-sendo num pressuposto do próprio ser, dando o sentido de uma totalidade deste, o que significa dizer que transforma a identidade, entendida como um contínuo dar-se "numa sucessão temporal, num dado atemporal - sempre presente (entendida como identidade pressuposta reposta numa sucessão temporal)" (Ciampa, 1986/2009, p. 180). Como se fosse possível congelar a identidade, estatizá-la, eternizá-la por meio da re-posição, que sustenta a "mesmice". A "mesmice" traduz este trabalho de re-posição como o movimento permanente de pressuposição de uma identidade, apoiada pelas expectativas/interesses generalizados de alguém (ou de um grupo/coletivo/sistema) capaz de reproduzir o social. "Algumas personagens que compõem nossa identidade sobrevivem, às vezes, mesmo quando nossa situação objetiva mudou radicalmente" (Ciampa, 1986/2009, p. 170).

Quando Ciampa (1986/2009) menciona o valor positivo da re-posição identitária enquanto direção aos indivíduos ao que acrescento e grupos, para pensarmos na identidade étnica, é necessário indicarmos que a re-posição identitária dos indígenas da Reserva Pataxó da Jaqueira se dá de forma consciente, numa articulação 
entre os costumes do passado, a memória coletiva da etnia; e o presente, com os novos sentidos conferidos pela própria comunidade, por se tratar da manutenção de costumes ressignificados ou reatualizados com o propósito de manter viva a memória da origem étnica, que lhes serve de referência e de fortalecimento sobre sua identidade étnica.

Thompson (1998) ressalta que os usos e costumes, particularmente fortes no século XVIII, eram, alguns, de criação recente e representavam a reivindicação de "novos direitos".

Assim, "no século XVIII, o costume constituía a retórica da legitimação de quase todo uso, prática e direito reclamado. Por isso, o costume não codificado e até mesmo o codificado - estava em fluxo contínuo. Longe de exibir a permanência sugerida pela palavra "tradição"” (Thompson, 1998, p. 16).

Segundo Thompson (1998), "as práticas e as normas se reproduzem ao longo das gerações na atmosfera lentamente diversificada dos costumes. As tradições se perpetuam em grande parte mediante a transmissão oral, com seu repertório de anedotas e narrativas" (p. 18).

Logo, não seria possível falarmos de mera reprodução de uma realidade remota, menos ainda de uma fetichização identitária com sentido negativo, que volta-se a impedir a emancipação do indivíduo/grupo que não atinge a condição de ser-para-si (tornar-se sujeito) capaz de sua própria determinação, na medida em que reduz os indivíduos/grupo em uma única personagem capaz de eliminar o jogo que articula diferença/igualdade. Ao contrário, o grupo étnico da Reserva Pataxó da Jaqueira escolheu de forma consciente usar seu traje tradicional, a arte indígena com novas pinturas criadas pelo grupo, retomar seus cânticos, rituais, voltar a morar em kijemes, resgatar sua própria língua, viver em contato com a natureza e recuperar a horta medicinal. Não como retorno ao passado, num gesto inconsciente de compulsão à repetição que se pretende manter inalterável ou fixar-se numa personagem atemporal,o grupo se autodeterminou em resgatar sua tradição, criou novas pinturas. E, com o resgate da personagem indígena pataxó tradicional, durante as palestras que realizam na reserva aos turistas, usam da oportunidade para derrubar falsos mitos e preconceitos que resistem quanto às diferenças fenotípicas que ainda surpreendem muitos que os visitam, e que guardam expectativas em encontrar a "personagem indígena pré-colonização", com cabelo liso e preto, que anda nu, vive tão somente da caça e da pesca, e é semialfabetizado. O grupo também modificou o padrão das características arquitetônicas de seus kijemes (introduziram porta, cama/redes, geladeira, televisão, luz elétrica, contrapiso sem acabamento, armário de cozinha para o armazenamento de mantimentos e panelas), usa roupas comuns da sociedade não indígena, celulares, carros, aprende línguas como o inglês e o espanhol, alguns indígenas falam inglês, espanhol, português e o patxôhã (língua indígena do povo Pataxó). Isto é, percebe-se diferente em seu modo de ser e de viver, mas não se priva de utilizar e adquirir "bens" e "conhecimentos" que lhe sejam úteis e facilitam a vida diária e sua visibilidade como cidadãos.

Por meio da autodeterminação dos indígenas da Reserva Pataxó da Jaqueira em resgatar a personagem indígena pataxó tradicional, foi possível também marcar a identidade-étnica nos serviços de etnoturismo da reserva, dando-lhes a direção da sustentabilidade econômica, ambiental e cultural, e inspirar as demais aldeias com condições (a depender de sua posição geográfica e outros aspectos) para o desenvolvimento do etnoturismo a seguir na mesma direção. Independentemente do projeto econômico adotado pelas demais aldeias pataxó, o trabalho desenvolvido pela Jaqueira tornou-se referência reconhecida de fortalecimento cultural e preservação ambiental a todas as aldeias pataxó.

Em sua autodeterminação, a personagem indígena pataxó tradicional expressa, na frase pronunciada pela indígena Iena, o sentido emancipatório do grupo quanto às opressões sofridas por perseguições, torturas físicas e psicológicas imputadas pela sociedade envolvente de não indígenas e a impossibilidade de viver com seus parentes, costumes e tradição em seu próprio território sagrado: "Parece que nasci de novo!", após trinta anos de afastamento de seus parentes em razão de sua fuga do episódio "Fogo de 51", retornando, com seu marido e filhos, ao convívio de seus parentes na Reserva Pataxó da Jaqueira.

A personagem indígena pataxó tradicional da Reserva Pataxó da Jaqueira carrega os costumes e valores da tradição de seu povo ou, se preferirmos usar a expressão do indígena Kamaiurá ao se referir à reserva, dando-lhe o sentido de "coração do povo Pataxó". Conseguimos enxergar, no pulsar das atividades da personagem indígena tradicional, o renascer de uma cultura, de um povo, que vê na retomada de seu território o retorno da esperança em voltar a assumir publicamente o que é sem nunca ter deixado de sê-lo: Pataxó.

\section{A luta por reconhecimento com sentido emancipatório}

O personagem guerreiro pataxó protagoniza a personagem indígena com direitos, dando origem à personagem pataxó da jaqueira, que luta por manter a personagem pataxó com reconhecimento.

Reconhecimento advindo da intensa luta por território e da organização política dos Pataxó, que terá desdobramentos para sua reconstrução identitária étnica por meio do intenso trabalho de divulgação realizado pela proposta de etnoturismo da Reserva Pataxó da Jaqueira, com o resgate de sua língua, o patxôhã (que é lecionado nas escolas para as crianças indígenas). Além disso, a retomada da pintura indígena, das danças, dos rituais e das histórias indígenas, o 
reconhecimento da capacidade dos Pataxó em realizar seus próprios projetos de sustentação ambiental, cultural e econômica, contrapondo-se à atribuição de "personagens estigmatizadas" (indígena preguiçoso; indígena sem sua cultura; indígena que desmata; indígena pescador; indígena caçador; indígena agricultor; indígena sem capacidade), determinada pela sociedade envolvente não indígena, numa afirmação perversa de reconhecimento identitário. É necessário esclarecer que as personagens "indígena pescador", "indígena caçador" e "indígena agricultor" são apresentadas aqui como estigmatizadas, por estarem associadas à "personagem indígena précolonização", com cabelo liso e preto, que anda nua, vive tão somente da caça e da pesca. Em outras palavras, nos remete à noção estigmatizadora do indígena "selvagem", "autêntico", "puro" e "incapaz de autodeterminação" presente na narrativa histórica descritiva do colonizador e reforçada pelo próprio poder público quando oferecem em maior número ou com maior frequência vagas de cursos de formação profissional tidas como "tradicionais", deixando de apresentar outras opções de formação profissional aos personagens indígenas Pataxó com reconhecimento.

Não é difícil compreender que, em tais situações, afirma Almeida (2005), "as políticas de identidade obedecem a razões político estratégicas de determinados atores sociais, direcionando os relacionamentos entre os indivíduos e entre os diferentes grupos que integram uma dada sociedade" (p. 131).

Lima menciona (2009) que, quando as políticas de identidade são utilizadas como instrumento de regulação, "estamos nos referindo às situações onde essas políticas são utilizadas de forma ideológica para a manutenção de uma realidade instituída, não possibilitando a expressão da subjetividade individual/grupal" (p. 150).

Há ainda um outro aspecto não menos importante das políticas de identidade, seu caráter emancipatório quando ampliam as possibilidades dos indivíduos, por meio da garantia de seus direitos, sua existência na sociedade, transformando-se em identidades políticas, quando estes constroem uma concepção de identidade para si mesmos, num processo que pode ter sua origem numa política de identidade em que têm diante de si a tarefa de fazer valer seus direitos e, a posteriori, a busca por novas formas de reconhecimento identitário. Lima (2009) salienta que "as identidades pressupostas oferecidas por determinadas políticas de identidade podem se tornar um impulso para a superação de outra personagem posta (segregadora) de forma negativa e limitadora" (p. 154).

Em contrapartida, o não reconhecimento diante da tentativa de construção de novas personagens produzidas reduz as identidades às personagens pressupostas num movimento de re-posição destas, o que configura o tipo particular de reconhecimento perverso, que se constitui na negação da humanidade de uma pretensão identitária que se contrapõe a uma dada realidade, garantindo ideológicamente sua manutenção e reprodutibilidade e a negação da alterização de uma identidade humana.
Nas experiências de desrespeito, que se delineiam pelas vivências de rebaixamento e humilhação social, "os seres humanos são ameaçados em sua identidade da mesma maneira que o são em sua vida física com o sofrimento de doenças" (Honnet, 2009, p. 219).

Portanto as reações emocionais negativas, como a vergonha ou a ira, a vexação ou o desprezo, desencadeiam "sintomas psíquicos com base nos quais um sujeito é capaz de reconhecer que o reconhecimento social lhe é denegado de modo injustificado" e que pode representar a "base motivacional afetiva na qual está ancorada a luta por reconhecimento" capaz de tornar-se, potencialmente, um motivo de resistência política, mas que dependerá, sobretudo, de como está constituído o entorno político e cultural dos sujeitos atingidos (Honnet, 2009, p. 220-224).

Em termos amplos, "o reconhecimento comporta, de forma geral, duas etapas: o que pedimos aos outros é, em primeiro lugar, que reconheçam nossa existência e, em segundo, que confirmem nosso valor" (Todorov, 1996, p. 94).

Poderíamos afirmar que a luta por reconhecimento, tanto no plano jurídico-moral quanto da estima social, constitui os processos emancipatórios que caracterizam as identidades políticas da etnia indígena Pataxó, na medida em que esta reivindica para si o reconhecimento jurídico do direito originário aos seus territórios em busca de melhores condições de vida e da manutenção de sua identidade étnica por meio da preservação de seus costumes e tradições. E, com o projeto de Etnoturismo implantado há mais de 24 anos na Aldeia Reserva Pataxó da Jaqueira, conquista o reconhecimento no plano da estima social ao demonstrar sua capacidade de gestão e resgate da cultura pataxó, formando gerações de lideranças que estão, atualmente, defendendo a causa indígena Como dizem os entrevistados, é o "coração do povo Pataxó" que soube divulgar seu trabalho e conquistar parceiros indígenas e não indígenas.

\section{Considerações finais}

Ao pensarmos a emancipação coletiva como algo inscrito na realidade social cotidiana de pessoas e grupos, ela se inscreve na busca e na luta por superar as condições desfavoráveis (injustiças, desrespeito aos direitos humanos, discriminações, violência na forma de dominação e exploração gerada pelo processo de valorização capitalista, desrespeito físico, cultural, ausência de participação política) por meio da fala e da ação coletiva, capaz de construir novos sentidos para a existência (Young, 1990).

A sociedade capitalista renova de modo constante e criativo suas formas de dominação social. Assim, a emancipação pode ser compreendida como processo provisório de articulação, lutas e conquistas parciais de identidades políticas em confronto com uma realidade que lhe é antagônica (Maia, 2011).

Nesse sentido, podemos falar sobre os resultados positivos da busca pelo povo Pataxó por reconhecimento 
como fragmentos emancipatórios, na condição de estarem circunscritos a condições históricas e políticas de reivindicações que são parcial e provisoriamente atendidas, na medida em que o jogo de forças sociais e interesses antagônicos são negociados em favor de determinados grupos sociais em detrimento de outros, ancorados num sistema capitalista que busca fazer prevalecer a manutenção do status quo para não ameaçar os interesses de grupos nacionais e internacionais com influência decisória nos campos da política e da economia.

Dialeticamente, os fragmentos emancipatórios abrem novos horizontes no futuro social, nem sempre previsíveis ou estimáveis quanto a seus resultados.
Contudo ampliam a capacidade de luta pela sustentação e afirmação da identidade étnica pataxó ancorada por sua cosmovisão e memória ancestral capaz de questionar os valores hegemônicos de uma geopolítica de matriz capistalista devastadora de seus territórios e cultura.

A subjetividade indígena pataxó interpela a psicologia social por um olhar e uma escuta clínica, na medida em que a convida a testemunhar o sofrimento e a luta política de um povo pela existência e permanência de seu éthos, a despeito de processos colonizadores; e a convoca a participar da construção de uma clínica social como sustentação da alteridade ameríndia capaz de apontar para outro projeto civilizatório.

\section{Clinic of identity: from pataxó cosmovision to the fight for emancipation}

Abstract: This article focuses on presenting the process of identity construction with emancipatory purpose based on the worldview and struggle for territory of the indigenous Pataxó people, the only ethnic group that managed to resist in the extreme south of Bahia. The research demonstrated that the struggle for recognition in legal, moral, and social value aspects constitute the emancipatory processes that characterize the political identities of the indigenous Pataxó.

Keywords: clinic, identity, worldview, territory, recognition.

\section{Clinique d'identité : de la cosmovision pataxó à la lutte pour l'émancipation}

Résumé : L'objet de cet article est de présenter le processus de construction d'une identité avec une signification émancipatrice à partir de la vision du monde et de la lutte pour le territoire du peuple autochtone Pataxó, le seul groupe ethnique qui a réussi à résister dans l'extrême sud de Bahia. Les recherches ont démontré que la lutte pour la reconnaissance des aspects juridiques, moraux et des valeurs sociales constitue le processus émancipateur qui caractérise les identités politiques du groupe ethnique autochtone Pataxó.

Mots-clés : clinique, identité, vision du monde, territoire, reconnaissance.

\section{Clínica de la identidad: de la cosmovisión pataxó a la lucha por emancipación}

Resumen: Se constituye el foco de este artículo presentar el proceso de construcción identitaria con sentido emancipatorio a partir de la cosmovisión y lucha del pueblo indígena Pataxó, la única etnia que logró resistir en el extremo sur de Bahía (Brasil). La investigación demostró que la lucha por reconocimiento tanto en el plano jurídico moral como el de estima social constituyen los procesos emancipatorios que caracterizan las identidades políticas de la etnia indígena Pataxó.

Palabras clave: clínica, identidad, visión del mundo, territorio, reconocimiento.

\section{Referências}

Aguiar, W. M. J., \& Ozella, S. (2006). Núcleos de significação como instrumento para a apreensão da constituição dos sentidos. Psicologia: Ciência e Profissão, 26(2), 222-245.

Almeida, J. A. M. (2005). Sobre a anamorfose: identidade e emancipação na velhice [Tese de Doutorado]. Pontifícia Universidade Católica de São Paulo, São Paulo, SP.

Angrosino, M. (2009). Etnografia e observação participante. Porto Alegre, RS: Artmed.
Barth, F. (1969). Introduction. In F. Barth (Ed.), Ethnic groups and boundaires: the social organization of culture difference (pp. 9-38). London: George Allen \& Unwin.

Becker, H. (1997). Métodos de pesquisa em ciências sociais. São Paulo, SP: Hucitec.

Brandão, C. R. (1984). Repensando a pesquisa-participante. São Paulo, SP: Brasiliense. 
Conselho Regional de Psicologia da 6 a Região. (Org.). (2010). Psicologia e povos indigenas. São Paulo, SP: CRPSP.

Dantas, E. M., \& Morais, I. R. D. (2008). Território e territorialidade: abordagens conceituais. Natal, RN: UFRN.

Düssel, E. (1997). Oito ensaios sobre cultura latinoamericana e libertação. São Paulo, SP: Paulinas.

Carvalho, M. R. G. (1977). Os Pataxó de Barra Velha: seu subsistema econômico [Dissertação de Mestrado]. Universidade Federal da Bahia, Salvador, BA.

Ciampa, A. C. (2009). A estória do Severina e a história da Severina (11a ed.). São Paulo, SP: Brasiliense. (Trabalho original publicado em 1986)

Figueiredo, L. C. (1996). Revisitando as Psicologias: da epistemologia à ética das práticas e discursos psicológicos. Petrópolis, RJ: Vozes.

Gaskell, G. (2008). Entrevistas individuais e grupais. In M. W. Bauer \& G. Gaskell(Eds.), Pesquisa qualitativa com texto, imagem e som: um manual prático (7a ed., pp. 64-89). Petrópolis, RJ: Vozes.

González Rey, F. (2009). O social na psicologia e a psicologia social (2a ed.). Petrópolis, RJ: Vozes.

Haesbaert, R. (1999). Região, diversidade territorial e globalização. GEOgraphia, 1(1), 15-39.

Hobsbawn, E., \& Ranger, T. (Orgs.). (1984). A invenção das tradições. Rio de Janeiro, RJ: Paz e Terra.

Honneth, A. (2009). Luta por reconhecimento (2a ed.). São Paulo, SP: Editora 34.

Jörg, S. (2011) Clínica da Identidade: um estudo sobre o sofrimento psicossocial coletivo [Dissertação de Mestrado]. Pontifícia Universidade Católica de São Paulo, São Paulo, SP.

Jörg, S. (2017). Clínica da Identidade: da cosmovisão pataxó à luta por emancipação [Tese de Doutorado]. Pontifícia Universidade Católica de São Paulo, São Paulo, SP.

Jovchelovitch, S., \& Bauer, M. W. (2008). Entrevista narrativa. In M. W. Bauer \& G. Gaskell (Eds.), Pesquisa qualitativa com texto, imagem e som: um manual prático (7a ed., pp. 90-113). Petrópolis, RJ: Vozes.

Lima, A. F.(2009). Sofrimento de indeterminação $e$ Reconhecimento Perverso [Tese de Doutorado]. Pontifícia Universidade Católica de São Paulo, São Paulo, SP.
Maia, A. A. M. (2011). Dimensões da emancipação em abordagens críticas e pós-críticas de currículo. Revista e-curriculum, 7(2), 1-19.

Maldos, P. R. M. A. (2010). Contribuição indígena na construção do nosso futuro comum. In Conselho Regional de Psicologia de São Paulo, Psicologia e povos indigenas (pp. 272-278). São Paulo, SP: CRPSP.

Malinowski, B. (1978). Argonautas do Pacífico Ocidental. In B. Malinowski, Malinowski (1884-1942): vida e obra (pp. 29-30). São Paulo, SP: Abril Cultural.

Moreira, J. O., Romagnoli, R. C., \& Neves, E. O. (2007). O surgimento da clínica psicológica: da prática curativa aos dispositivos de promoção da saúde. Psicologia, Ciência e Profissão, 27(4), 608-621.

Oliveira Filho, J. P. (1999). Ensaios em antropologia histórica. Rio de Janeiro, RJ: Editora UFRJ.

Pataxó, N. (2011). As guerreiras na história Pataxó. Brasília, DF: Funai.

Poutignat, P., \& Streiff-Fenart, J. (1998). Teorias da etnicidade. São Paulo, SP: Editora da Unesp.

Ribeiro, D. (1970). Os índios e a civilização: a integração das populações indígenas no Brasil moderno (2a ed.). Rio de Janeiro, RJ: Civilização Brasileira.

Sampaio, J. A. L. (2010). Sob o signo da cruz. Cadernos do LEME, 2(1), 95-176.

Santilli, M. (1999). Natureza e situação da demarcação das terras indígenas no Brasil. In C. Kasburg \& M. Gramkow (Orgs.), Demarcando terras indigenas: experiências e desafios de um projeto de parceria (pp. 23-44). Brasília, DF: Funai.

Thompson, E.P.(1998). Costumes em comum.São Paulo,SP: Companhia das Letras.

Todorov, T. (1996). A vida em comum. Campinas, SP: Papirus. Young, I. M. (1990). Justice and the politics of difference. Princeton: Princeton University Press.

Recebido: 19/11/2019

Revisado: 29/07/2021

Aprovado: 27/09/2021 